\title{
Rethinking place-making: aligning placeness factors with perceived urban design qualities (PUDQs) to improve the built environment in historical districts
}

\begin{abstract}
Understanding the concept of place is critically important for urban design and place-making practice, and this research attempted to investigate the pathways by which perceived urban design qualities (PUDQs) infuence placeness factors in the Chinese context. Twelve hypotheses were developed and combined in a structural equation model for validation. The Tanhualin historical district in Wuhan, China was selected for the analysis. As a result, place attachment was verifed as a critical bridge factor that mediated the infuence of PUDQs on place satisfaction. Among the fve selected PUDQs, walkability and space quality were revealed as the most infuential factors associated with place attachment and place satisfaction. Accessibility was actually indirectly benefcial to place-making via the mediation of walkability. Corresponding implications and strategies were discussed to maintain the sense of place for historic districts.
\end{abstract}

Introduction

Since the 1970s, the notion of "Place" has earned increasing attentions from the academics especially in social science. In many historical places, the 'sense of place' (Jivén and Larkham 2003), or the so-called 'genius loci' (Norberg-Schulz 1980), tends to emerge when a vivid living scenario coincides with the richness of townscape through the intertwining of activity, image, and form (Carmona et al. 2003). The relationship between humans and space is anchored in dwellings (Heidegger 1975), and therefore, people's judgement of the urban space refers not only to the built environment attributes but also to the perceptive dimensions in which meaningful representations of, and emotional connections to, the people and the environment are established (McCunn and Giford 2018). However, from the second half of the twentieth century, many East Asian cities have enthusiastically adopted enterprising plans to strive to promote themselves as regional and global hubs (Shim and Santos 2014). For economic and political purposes, substantially increasing number of resources and corresponding amount of effort have been invested to establish urban spectacles and landmarks, while the uniqueness and local favour of a place has been ruthlessly eradicated, with standardized and homogenized urban images becoming overwhelming (Morley 2009). The unique individuality and original characteristics of historical places have been replaced by what is called 'Space Left Over After Planning' (SLOAP) or 'Lost Space' (Trancik 1986), resulting in an increasing sense of 'Placelessness' as described by Relph (1976). For instance, since the 1980s, in China, the ongoing regeneration projects have swept away a large percentage of historical districts (Wu 2003), leading to an impending crisis of urban identity on a much larger scale even than what happened in the Western countries during the 1960s and 1970s (Chapman and Larkham 1999).

Accordingly, the role of "Placeness" contributing to urban life and social cohesion has been increasingly noted by many scholars across disciplines. The characteristics of a place, such as liveability, quality, and identity, have begun to appear frequently in the discourses of urban planning, environmental psychology, and tourism management to accentuate the tie between people and place (Proshansky 1978; Gospodini 2004; Sepe and Pitt 2013, 2014; AbouShouk et al. 2017). For instance, placeness and other related concepts have often been mentioned in the environmental psychology literature, and person-environment $(\mathrm{P}-\mathrm{E}) \mathrm{ft}$ models have been proposed to correlate with psychological well-being (Phillips et al. 2010). The place-related psychological dimensions, such as place attachment, place identity, and place satisfaction, have been defined with 
psychometric approaches (Ramkissoon et al. 2013; Jorgensen and Stedman 2006). In the tourism literature, the term "sense of place" or "placeness" has been emphasized either as a predictor to behavioural intentions or a mediator that affects some aspects of tourism (Yuksel et al. 2010; Ram et al. 2016; Lee and Shen 2013). In the urban planning literature, Manzo and Perkins (2006) revealed that cultivating positive meanings and emotional ties to places promotes preservation behaviours of place identities and suggested paying more attention to the interaction between place meanings and planning impacts. It has been emphasized that the subtlety of how people perceive a place is an important component of social dynamics and is critical for proper decision-making and sustainable planning (Tan et al. 2018; Addison et al. 2013). Accordingly, urban design approaches such as mixeduse, diversity, walkable districts, easy access, and convenient transportation options, have been positively incorporated in place-making implementations (Stedman 2003). Some specifc built environment attributes (e.g. accessibility of the nearest activity centre, sidewalk quality, street density, and land use) have been adopted to investigate people's perception of place meanings and their travel behaviours (Zhang and Zhang 2018).

Although these previous studies have well documented place-related concepts and urban design strategies individually, few attempts have been made to associate these two groups of factors and to evaluate how perceived urban design qualities (PUDQs) contribute to place-making practice. Moreover, PUDQs as predictors of place attachment have not been well studied, and far less attention has been paid to how place attachment plays a bridging role between perceived urban design qualities and place satisfaction, which is considered as an important outcome measure of placemaking implementation (Zenker and Rütter 2014). In order to fill these knowledge gaps, this study aims to investigate the pathways by which PUDQs influence placeness factors in the Chinese context with quantitative estimations. Twelve hypotheses were developed to establish a theoretical model for validation via structural equation modelling (SEM). This research takes a case study of a historical district in Wuhan, a representative city in Central China, as it has witnessed not only booming momentum in urban design implementation but also rapid change in cityscape. Some critical contributions to the existing literature are realized in several ways. Theoretically, this research attempts to establish a conceptual model that involves important practical urban design strategies to explore comprehensive respondent effects on place-making in historical districts. Empirically, structural equation modelling is adopted to simultaneously analyse multiple sets of pathways via which PUDQs influence place satisfaction with various latent variables rather than individual observation variables, resulting in more accurate estimations. Using evidence-based methods, this study is beneficial to combine the weight of different urban design strategies in different scenarios for place-making optimization.

The remainder of this paper is organized as follows. The "Literature review" section briefly reviewed the literature on place-related concepts and PUDQs, and a series of hypotheses were proposed to establish a theoretical model. "Data and methods" section introduced the general methods, instrument of variables, data preparation, and background of the selected case. The "Analysis procedure" section introduced the procedures of data analysis. The "Results" section and "Discussion" section presented results that summarized the main findings along with discussions and implications. The "Conclusion and recommendations for future research" section concluded the article with research limitations.

Literature review

Place-making 
The term place-making has been variously defined and developed as a concept with the specific contexts of urban development. Dupre (2019) summarized some important findings through comprehensive literature review of placemaking over the past 25 years, pointing out that the term of place-making has become more complex and overarching rather than a general concept as before. Its connotation is beyond shaping physical built environment and also extends into a more comprehensive discourse associated with policymaking, investment, and cultural revitalization through different kinds of design process (Martin 2003; Schneekloth and Shibley 1995). Some other notions related to perceptions, such as experience, collective memory, narratives, and etc., are also linked with the concept of place (Habibah et al. 2013). Among those frequently mentioned keywords, sense of place, place identity, place creation, community, and neighbourhood are usually kept as stable sub-concepts with transdisciplinary characteristics, and also intertwine with comprehensive social concerns (Dupre 2019; Buckman 2016; Hassen and Kaufman 2016; Lombard 2014; Pancholi et al. 2015; Motloch 1990; Friedmann 2007).

Through formal and informal place-making processes, the geographic features of a place could be strengthened when spaces are endowed with meaningful characteristics (Schneekloth and Shibley 1995). Place-making could be integrated with urban design implementations and processes to create liveable neighbourhood with affiliating ambience in which people enjoy daily lives whenever they work, visit, or take leisure activities (Kelly et al. 2016). A whole set of tools, e.g. improving public spaces and infrastructures within the community, could be adopted to achieve this goal by design professionals and governments. Four types of place-making oriented urban design strategies have been proposed, from physical attributes of the place to more intangible aspects, such as branding, marketing, and advertising (Williams and Lew 2015; Lew 2017).

Placeness factors

The notion of "sense of place" or "placeness" initially comes from the cultural geography literature and is defined as a composite emotion that tends to manifest an inclined feeling or behaviour for a space or a special physical setting (Othman et al. 2013; Jorgensen and Stedman 2006); it also refers to the affective, cognitive, and behavioural components of psychological aspects (Morgan 2010; Scannell and Giford 2010). Over time, these place-related concepts have been incorporated into the planning and architecture fields, involving top-down intentional approaches to shape people's perceptions of a place (Cilliers and Timmerans 2014). In this research, the definition of place-making is enhanced from the perspective of urban design professionals, referring to a more thoughtful and purposeful approach to improving both the built environment and the embedded cultural characteristics. Furthermore, we combine our research approach with the tradition of cultural geography, since a successful place-making implementation should not merely consider the improvement of physical environments but should also acknowledge the subjective experience of inhabitants and social values.

A place in the urban setting could be considered as part of the physical reality in which people's subjective attributes might be incorporated, such as emotions, beliefs, and behavioural characteristics (Stedman 2003). Since placeness plays a vital role in connecting the physical and spiritual world, the emotional interactions that people establish with a place affect the way it is perceived and interpreted (Scannell and Giford 2010). The notion of place attachment refers to the emotional bond to a particular place (Stedman 2003; Fan and Qiu 2014) and related connotations embodied in the physical settings, emphasizing the potential role of a place in supporting worthwhile activities (Williams and Vaske 2003) and facilitating desired experiences of the public (Kyle et al. 2004). Other sub-concepts, such as place dependency and place identity, are oftentimes used in difference scenarios either as the synonym for place attachment or as its components 
(Jorgensen and Stedman 2006; Tsai 2012). The environmental psychology literature has addressed place attachment and its related environmental features and social behaviours and has discussed why people experience a sense of belonging to a specific place, indicating the potential of combining place-related issues with urban design discourse (Lalli 1992).

The term "place satisfaction" also has appeared in discussions of environmental psychology, tourism management, and leisure and recreation (Sirgy 2010; Kyle et al. 2004). A broader definition of place satisfaction refers to a comprehensive evaluation of the perceived quality of a place in meeting one's preferences for the spatial characteristics of a place and affiliated attributes like management, services, and other social aspects (Stedman 2002, 2016). Correlated with place attachment, high place satisfaction tends to be associated with positive outcomes, such as people showing a higher preference for a place and staying there longer (Hidalgo and Hernández 2001). In this regard, place attachment could be assumed as an antecedent of place satisfaction (Zenker and Rütter 2014; Zenker et al. 2013). In the tourism literature, meeting the needs of visiting a place with symbolic meanings is needed for tourists and would influence their satisfaction to a destination (Kwenye and Freimund 2016). Prior studies indicated that place attachment exerts a significantly positive efect on tourist satisfaction and further on loyalty towards a destination (Ramkissoon et al. 2012; Yuksel et al. 2010; Prayag and Ryan 2012). In this research, place attachment and place satisfaction are involved as two important placeness factors because the compositional association with place-protective attitudes is helpful to facilitate humanized and pro-environmental ideas and actions in historical districts (Chapin and Knapp 2015).

Perceived urban design qualities (PUDQs)

A plethora of literatures have proposed PUDQs of the built environment as important concerns for place-making, including convenience, safety, accessibility, comfort, attractiveness, and maintenance (Ewing and Handy 2009). For instance, prior studies have indicated that environment pleasurability and space quality were significantly associated with physical activity behaviours (Lu et al. 2018; Lindelöw et al. 2014). Physical settings such as squares, streets, buildings, and all other related morphological elements in urban spaces function as a city's hardware for fundamental socioeconomic functions - living, working, services, recreation, etc. - and human activitiescommunication, movements, emotional experience, etc. - that physically and cognitively influence the affective experience in a place (Gehl 2011). As different human activities mix in the urban space, highly integrated coalescence and symbiotic interaction between urban functions and place meanings emerges and influence people's perceptions (Besussi et al. 2010). More understanding about how human activities take place at various levels could also be obtained from urban functions and management, which act as software to reflect urban organization and policy-making (Voorde et al. 2011). For instance, one study revealed that shopping and leisure activities could strengthen visitors' legibility of and dependency on a place (Shim and Santos 2014). Conversely, the dislocation of space and function may also negatively influence people's experiences in a place that should have been attractive, causing spatial conflicts and disturbances (Zakariya et al. 2015). The perceived quality of a place is relevant to the interactive effect between human beings and built environment attributes and refers to how a place is regulated through the sensed service quality, maintenance of the physical environment, and other sensed orders related to place management (Kalali 2015) that either enhance or deteriorate a place.

Promoting walkability is regarded as another important urban design concern (Credit and Mack 2017; Johansson et al. 2016). A friendly walking environment could facilitate spontaneous activities and prompt social communication. Gehl (2011) described how incremental improvements with pedestrian-oriented strategies transformed Copenhagen from a car-dominated city to a human-scale 
city. Pedestrianoriented urban environments are beneficial for the working class, whose transportation and employment choices are constrained, and could also minimize the commute cost between work and leisure activities for the creative class (Florida 2002). There is a positive relationship between walkability and economic value (Pivo and Fisher 2011), as the diversity of people and businesses create 'effective economic pools of use' by increasing foot traffic and window shopping that foster patronization of stores, restaurants and cafes. Krizek (2003) pointed out some common characteristics of a well-accepted walkable environment, such as high density, small lots, mixed-use areas, and access to parks.

Among the various definitions across disciplines and analytical contexts, accessibility offers the logistics that enable people to flow conveniently, establishing an equal, diverse, and efficient communication system that helps improve people's transportation (Marshall 2004). For practical purposes, the "Three D's" principle included the concept of destination accessibility (Cervero and Kockelman 1997). Accessibility is also regarded as helpful to increase the probability of attracting more people and casual opportunities for business. The key attributes of an accessible place include strategic locations, vicinity of transit nodes, and a networked system. The connotations of accessibility might vary based on how it is measured (Kwan 1998). Place-based metrics such as distance, time, and cost are usually applied to measure getting to a given destination (Horner 2004). However, it is necessary to account for individuals' personal perception and those constraints that might limit their ability to visit a place (Miller 1991). Therefore, this paper adopts perception-based measures that balance individual constraints with subjective and contextual factors that may influence accessibility outcomes.

The hypotheses and conceptual model

Two place-related dependent factors - place attachment (PA) and place satisfaction (PS) - and five predictive factors of perceived urban design qualities - walkability (WK), accessibility (AC), space quality (SQ), urban function (UF), and management (MA) - are proposed, with all the corresponding variables. According to the above literature reviews, a series of hypotheses are listed below in a structural model to test the networking associations among these described factors (Fig. 1).

H1. Walkability is positively associated with Place attachment.

$\mathrm{H} 2$. Accessibility is positively associated with Place attachment.

H3. Space quality is positively associated with Place attachment.

H4. Urban function is positively associated with Place attachment.

H5. Management is positively associated with Place attachment.

6. Space quality is positively associated with Walkability.

H7. Accessibility is positively associated with Walkability.

H8. Place attachment is positively associated with Place satisfaction.

H9. Walkability is positively associated with Place satisfaction.

H10. Space quality is positively associated with Place satisfaction.

H11. Urban function is positively associated with Place satisfaction.

H12. Management is positively associated with Place satisfaction. 


\section{FIGURE 1 NEAR HERE}

Data and methods

General methods

This study explored the pathways by which PUDQs influence placeness factors. Rather than measuring physical attributes, we applied psychometric approaches to examine subjective attitudes in measuring perceived urban design qualities. Measuring instruments were developed with descriptive items according to the existing literature and practical purposes. Confirmatory factor analysis (CFA) was employed with measurement models for all the latent variables to identify these factors. Reliability and validity should meet the required criteria before conducting a structural model for regression analysis. Then, a structural model was established connecting all dependents and predictors. If the model $\mathrm{ft}$ was accepted, multiple regressions were applied for path analysis to estimate the alignment between the PUDQs and placeness factors.

\section{Case background}

Tanhualin historical district, which is situated to the north-east of Wuchang town centre in Wuhan City, China, was selected for a case study. Tanhualin has a unique townscape and is a highly important historical district in China (Fig. 2). Bounded by Zhongshan Road to the east and Desheng Bridge to the west, Tanhualin includes several communities and covers the long, narrow spaces between Garden Hill and Pangxie Hill. Tanhualin's main street is east-west oriented, approximately $1.2 \mathrm{~km}$ long and 3-5 m wide. Since the $1860 \mathrm{~s}$, when ports along Yangtze River were opened to Western countries, dozens of historical buildings have nestled near the main street. By the 1930s, the scale and pattern of Tanhualin district had crystallized, attaining an area of nearly 70 ha.

\section{FIGURE 2 NEAR HERE}

The Pangxie Ridge in the northern part of Tanhualin is where the original Wuchang city wall was built. Different types of historical buildings were built along the relics of this city wall in picturesque disorder. Hillside houses, courtyards, hill steps, paths and alleys can be seen everywhere, structuring a spatially rich network system (Figs. 3,4 ). With an integrated natural and built environment, Tanhualin historic district contains a large number of historical, cultural, and architectural relics, one of which is the Chongzhen Church, built by British missionaries in 1865 as the first church in Hubei Province. Later, the Renji Hospital was built and affiliated with the British parish. In 1868, Episcopal missionaries from the United States arrived in Wuchang and founded a boarding school for boys. In 1871, the Boone Memorial School was established and later became Boone College (Wenhua College). In 1880, Italian missionaries enlarged their bishop's offices, churches, schools, and hospitals near Garden Hill. In 1890, Swedish arrivals established a missionary base near the Tanhualin main street, including a gate tower, bishop's building, consulate house, and clergy room. The Swedes also established the nearby Zhenli Middle School. As seen, individuals from the United States, Italy, and Sweden set up their own parishes in this area, erecting a number of buildings related to religion, education, health care, and residence. These buildings featured a mixture of European styles and local Jiangxia style dwellings, shaping the streetscape of Tanhualin district with unique characteristics. Near-modern Chinese celebrities also chose to live or work in this district, resulting in many residential buildings that contained local characteristics.

Figures 3 \& 4 near here

After 1949, the newly established government redistributed original buildings by means of confiscation, expropriation, expropriation and redemption. Due to the influx of a large number of 
populations, the housing condition was not able to meet residents' needs, and they began to make extension or transformation on these buildings. Some plots were replaced with new housings.

Despite of these changes, the majority of the layout of Tanhualin area is still preserved with a large number of original buildings which were constructed since the Concession period, presenting a strong historical continuity and rich context of local urban morphology. Besides, the pedestrianoriented public spaces in Tanhualin area with authentic culture and traditional lifestyles make it a suitable place for this study.

Instruments

This research used a multi-item measurement for each construct via the following steps. First, all the factors were measured with the following questions based on evidence from the above literature reviews adapted for the research context. Second, items were measured by a structured questionnaire. After the questionnaire was drafted, a pre-test was performed with a sample of 52 respondents to eliminate terminology and ambiguous expressions, ensuring easy readability for respondents. Finally, twenty-four items (Table 1 ) were retained in the flnal survey, which used a seven-point Likert scale ranging from strongly disagree (1) to strongly agree (7).

TABLE 1 NEAR HERE

Surveys

The current study data were collected by a research team through a survey conducted between May and June 2018. Before the survey took place, this research team flnished the onsite fleld investigation and documentation (Fig. 4). Each student of the research team distributed the survey independently on weekdays under good weather conditions. The survey lasted for three weeks, with even distribution throughout the Tanhualin area. The research team selected survey respondents through two stages. In the flrst stage, 50 housing units were randomly selected within the Tanhualin area. In the second stage, 5-10 households were randomly selected from the selected housing units according the probability proportionate to population size principle, and one adult household member was chosen as the survey respondent using Kish Grid method. According to Trentelman (2009), place attachment was defIned as an indicator of local residents' rootedness to the living environment, referring to their emotional bonds to the communities. Therefore, we adopted this precondition and only considered local residents in this current study. The purpose was to validate a local model, which is necessary for further development. The more generalized model describing the associations between placeness factors and PUDQs will be examined by taking other stakeholders (e.g. visitors, tourists, salesmen, and street vendors) into account in our future research for next step. The study eventually resulted in 397 total surveys completed by individual respondents, who had live there long enough and knew Tanhualin well. Each respondent received a gift after filling out the questionnaire. All respondents were properly guaranteed their privacy and anonymity.

Among the raw data, 13 completed surveys were checked due to unexpected errors and were removed from the entries. Eventually, 384 completed surveys were selected for the final report with descriptive statistics below (Table 2). Among the final entries, there were 179 males (46.6\%) and 205 females $(53.4 \%)$, with an average age of 31.6 (std. $=5.3)$. Among the respondents, $59.9 \%$ of them are under 50 years old, and $51.2 \%$ of them have received education from college or above. Data entry was checked to ensure the absence of outliers or missing values for the measured variables. The approximate normality of each continuous variable was examined beforehand to meet the acceptable criteria (Hair et al. 2010) with skewness (value between -1 and +1 ) and kurtosis (values between -5 and +5$)$. 


\section{TABLE 2 NEAR HERE}

Analysis procedure

Measurement model

Confirmatory factor analysis (CFA) was applied to the measurement model for each factor, specifying the posited relations of the observed variables to the latent factors. CFA was conducted to extract the common variance into a single factor. According to Hair et al.'s (2010) recommendations (1) all the item loadings should be significant and exceed 0.5 , and the cut-of factor loading should be 0.60 , while items with cross-loadings over 0.4 should be rejected as a means of item juxtaposition among several constructs; (2) convergent validity should be applied to reconfirm the qualification of confirmatory factor analysis. The internal consistency of all items within each construct could be measured using composite reliability (C.R.), whose value should be within the domain of 0.7 and 0.95 as suggested; (3) the average variance extracted (AVE) by each construct should exceed 0.50 .

\section{TABLE 3 NEAR HERE}

In Table 3, a list of goodness-of-fit (GFI) measures, including chi-square ( $\chi 2$ ), normed chi-square index ( $\chi 2$ / df), root mean square error of approximation (RMSEA), standardized root mean squared residual (SRMR), comparative fit index (CFI), and Tucker-Lewis index (TLI), are presented as acceptable according to the CFA criteria. Other indices were also accepted, as the factor loading of all items within the seven factors ranged from 0.630 to 0.928 and was significant at the $p<0.001$ level, the AVE values for all factors ranged from 0.525 to 0.802 , and the C.R. values ranged from 0.767 to 0.924 , all assuring convergent validity for all factors.

Discriminant validity was also tested to examine whether individual factors could be adequately distinguished from one another. The result was accepted as the suggested criteria (Fornell and Larcker 1981), since the AVE square root of each factor in bold along the principal diagonal (Table 4) is higher than the corresponding correlations of other constructs, namely, the of-diagonal elements in the corresponding rows and columns, assuring discriminant validity since this construct is more closely related to its measured items than to the other constructs.

\section{TABLE 4 NEAR HERE}

Model-flt

The Mplus 7.0 software was used to test the proposed structural model with the method of maximum likelihood estimation, and the result was good for acceptance according to the goodnessof-ft (GFI) measures, demonstrating the model's high quality (Table 5). All the advised model-ft indices were within acceptable criteria, including chi-square $\left(\chi_{2}=451.221\right)$, normed chi-square index $(\chi 2 / d f=1.928), R M S E A=0.049, S R M R=0.054, C F I=0.964$, and $T L I=0.958$. Since the chi-square has been found to be over-estimated due to its sensitivity to sample size (Byrne 2001), causing unacceptable model $\mathrm{ft}$ indices, the Satorra-Bentler likelihood estimation was adopted to further optimize the result (Bryant and Satorra 2012): $\chi 2=396.850, \chi 2 / \mathrm{df}=1.696, \mathrm{RMSEA}=0.043$, SRMR=0.053, $\mathrm{CFI}=0.970$, and $\mathrm{TLI}=0.964$.

\section{TABLE 5 NEAR HERE}

Results

Descriptive 
The following sections provide descriptive statistics for the observed variables in the survey (Table 6). According to the requirement of approximate normality of each continuous variable, the skewness and kurtosis were all within acceptable criteria (Table 6). The mean of each variable item is presented in Fig. 5. The mean of each factor was also calculated for comparison, resulting in the scores of walkability and space quality of approximately 5.5 , urban function and management of approximately 4.7 , accessibility of approximately 5 , place attachment of approximately 5.4 , and place satisfaction of approximately 5.7.

\section{TABLE 6 NEAR HERE}

\section{FIGURE 5 NEAR HERE}

Hypothesis test (direct effect)

The proposed hypotheses in the model were tested by examining the path coefficients and related statistical significance (Fig. 6). The results in Table 7 reveal that 9 of the total 12 hypotheses were supported according to the $p=0.05$ significant level, and 6 of them were significant at the $p=0.001$ level.

\section{TABLE 7 NEAR HERE}

\section{FIGURE 6 NEAR HERE}

As the results indicated, walkability $(\beta=0.411, p<0.001)$ space quality $(\beta=0.304, p<0.001)$ and urban function $(\beta=0.140, p<0.05)$ were important antecedent variables that directly, positively, and significantly affected place attachment, with a moderately high explanatory power ( $R 2=0.551)$. The increase of these predictors mentioned above will make place attachment increase on various degrees.

Space quality $(\beta=0.574, p<0.001)$ and accessibility $(\beta=0.114, p<0.05)$ were important antecedent variables that directly, positively, and significantly affected walkability, with a moderate explanatory power (R2=0.386).

\section{Mediation test (indirect effect)}

To avoid biased estimations due to the possible multivariate non-normal distribution, the bootstrap method was used to estimate the mediation effects between the described factors. In the $95 \%$ confidence interval, the result revealed that 9 of the total 11 hypothesized mediation effects were supported according to the bootstrap criteria that the path estimate of zero should not be contained within the confidence interval (Table 8); only 2 hypothesized mediation effects were rejected. According to the results, walkability (Bindirect=0.141) had a significant indirect affecting place satisfaction via place attachment. The result shows that urban function ( $\beta$ indirect $=0.048$ ) also had a significant indirect affecting place satisfaction via place attachment. For space quality, it ( $\beta$ indirect $=0.169$ ) had a significant indirect affecting place satisfaction via walkability, and it ( $\beta$ indirect $=0.104$ ) had a significant indirect affecting place satisfaction via place attachment. Space quality also ( $\beta$ indirect $=0.081$ ) had a significant indirect affecting place satisfaction via walkability and place attachment. For accessibility, it ( $\beta$ indirect $=0.034$ ) had a significant indirect affecting place satisfaction via walkability, and it ( $\beta$ indirect $=0.016$ ) had a significant indirect affecting place satisfaction via walkability and place attachment. Finally, the result turned out that space quality ( $\beta$ indirect $=0.236$ ) had a significant indirect affecting place attachment via walkability, and accessibility ( $\beta$ indirect $=0.047$ ) had a significant indirect affecting place attachment via walkability. 
Total effect

The total effect is measured by summing up the significant direct effect and all significant indirect effects upon a certain factor, with the results shown in Table 9.

\section{TABLE 9 NEAR HERE}

for place attachment, its predictors were space quality ( $\beta$ total $=0.540)$, walkability ( $\beta$ total $=0.411$ ), urban function ( $\beta$ total=0.140), and accessibility ( $\beta$ total=0.047), according to the descending order of the total degree of influence. For place satisfaction, its predictors were space quality ( $\beta$ total $=0.481$ ), walkability ( $\beta$ total $=0.435)$, place attachment ( $\beta$ total $=0.342$ ), management ( $\beta$ total $=0.185$ ), accessibility ( $\beta$ total $=0.050$ ), and urban function ( $\beta$ total $=0.048$ ), according to the descending order of the total degree of influence. For walkability, its predictors were space quality ( $\beta$ total $=0.574$ ) and accessibility ( $\beta$ total=0.114), according to the descending order of the total degree of influence.

\section{Discussion}

Existing studies on urban planning and environmental psychology have highlighted the important role of placeness, yet the pathways by which urban design strategies and corresponding perceived urban design qualities influence placemaking implementation remain poorly understood. In this research, we used survey data in the historical district of Wuhan to establish a valid structural model aligning placeness factors with PUDQs, and 9 of the total 12 direct influences from PUDQs on placeness factors (hypotheses) were verified with an explanatory power. In the proposed model, place attachment was verified as a critical component that mediated the influence of several PUDQs on place satisfaction. Other than presenting consistency or discrepancy with some early studies, our findings also take a further step in investigating the pathways by which PUDQs are associated with placeness factors. Of the five proposed PUDQs, walkability and space quality were the two most influential factors associated with both place attachment and place satisfaction. Some prior studies have reported the general positive role of accessibility in place-making practice (Curtis and Tiwari 2008), while our findings revealed that accessibility was actually indirectly benefcial to place-making via the mediation of walkability. This finding empirically explicated the mechanism by which accessibility contributes to urban design practice and reconfirmed the importance of walkability as a critical urban design strategy. The results also showed that the diversity of urban function directly influenced place attachment instead of place satisfaction, and management had direct influence on place satisfaction rather than on place attachment. These interesting findings made conceptual and empirical contributions that either reconfirmed or modified some previous understandings of urban design strategies applied to historical districts, especially in the Chinese context.

Place attachment as a key factor

The results validate the importance of place attachment as a critical mediator between PUDQs and place satisfaction. Unlike Ramkissoon and Mavondo's (2015) study that assigned satisfaction as the determinant of place attachment, we conversely attempted how place attachment exerted effect on place satisfaction, which should be reasonably considered as the outcome measure of place-making. Our attempt is more for the purpose of prediction and the result is positive and significant as we expected. This finding is basically concurrent with some international studies in Singapore (Tsai 2012) and Spain (Campón-Cerro et al. 2015). In historical places, place attachment could influence not only the economic function (business exchange between local merchants and customers) but its social function (communication and interaction between local residents and visitors). The similar contention could be found in previous studies which indicate that meanings constructively embedded within individual's mind from unique destination attributes play a significant role to 
enhance one's experience and increase the level of satisfaction with a place (Williams and Lew 2015; Ram et al. 2016). Subsequently, it is the other way round that positive feedback of satisfaction enhances the identity of a place and promotes its brand (Prayag and Ryan 2012). Taking the Tanhualin district, for instance, although faded from its most glorious age, it epitomizes the history of modern architecture in Central China with profound cultural connotations and is still a cultural symbol and one of the most important spiritual destinations of Wuhan, attracting innumerable tourists from around China every year. Although tourism and business often prevail in urban regeneration practices, the protection and carrying forward of cultural value and historical authenticity should be regarded as the source of power to sustain revitalization in historical places. Planning practices in historical districts should be cautiously guided with emphasis on place dimensions. Especially, it is critical to remain vigilant about the so-called 'aestheticization of everyday life' and its potential injury to the characteristics of historical places (Featherstone 2007); this trend has become the most fashionable carrier for cultural consumption grafted to a particular period of time and is often utilized as a gimmick to work with the production of space (Lefebvre 1991). For instance, the New-World (Xin-Tian-Di) model in Shanghai has been widely duplicated in many cities in China, regardless of the distinction of geography, culture, and history. Consumption of historical places under the operation of commercial capital is essentially driven by business interests, although sometimes it is labelled with cultural revival. However, if economic indicators-GDP, income, taxes or competitive measures-account for dominance (e.g. rankings and vanity), the most important aspects - the communal well-being and satisfactory living of citizens in a humanized public place-could be more or less neglected (Luque-Martínez and Muñoz-Leiva 2005). In the process of market-oriented development, unilateral pursuit of economic effciency might inevitably cause conflict between public and private interests. The weakening of place attachment in historical districts would exacerbate existing problems and lead to the destruction of social cohesion, eventually negatively influencing the local economy in this area.

Coupling urban design's walkability and space quality with place attachment

As the results indicated, of all the described PUDQs, walkability and space quality simultaneously served as the two most influential components associated with place attachment, which further mediated compositional effects of PUDQs to place satisfaction (PS). The result was well proved by the survey, in which the respondents gave higher ratings to walkability ( $\mu w k=5.54)$ and space quality ( $\mu \mathrm{sq}=5.48$ ) than other predicting PUDQs. The capillary paths and lanes that lead in various directions and intersect with the Tanhualin main street are very impressive walking experiences. $\mathrm{A}$ well-woven and clearly structured network is organically organized to connect important public buildings and nodes, forming a series of continuous public spaces with distinctive atmosphere. This finding is also consistent with some prior studies, indicating that people feel please when walking in the urban settings with scenic aspects, cultural meanings, and local characteristics (Abou-Shouk et al. 2017). Furthermore, the results indicated that space quality simultaneously exerted significantly direct influence on walking experience, place attachment, and place satisfaction. This finding is in compliance with previous studies of related disciplines (Wynveen et al. 2012; Prayag and Ryan 2012). Although prior studies have often emphasized the critical role of walkability in policymaking, our study revealed that space quality had a higher total effect on place satisfaction, reminding researchers of the importance of properly attending to physical design strategies. Therefore, we highly recommend a deep combination between space quality and walkability, because a systematic coupling effect rather than simply adding the two without conjunction would be more powerful to support a good place-making implementation; in other words, a well-designed place must also be suitable for walking and other human activities. As the success of a walkable place is affected by how it accommodates human activities in an efficient, comfortable, and healthy 
manner, a comprehensive strategy that simultaneously invests in physical settings, infrastructure, and activity-based functions would be helpful, as proven by prior studies (Jorgensen and Stedman 2006). In our case, the results indicated a mismatch among the described factors in the Tanhualin district. For instance, the increasing hypocritical beautification for commercial advertisement purposes was encroaching on the original image of this area and stood in contrast with problems including lack of places for comfort and relaxation, low quality of building maintenance, inferior sanitary conditions, little consideration for architectural amenities that help prevent unpleasant natural conditions, and absence of human-scale details such as ramps and hand rails. These problems detracted from a pleasant walking environment and prohibited the formation of place attachment to this historical place.

Aims of optimizing accessibility

Although the results indicated that accessibility had no direct influence on place attachment, implying that people may still hold positive attitudes towards Tanhualin even though it is not easy to get there, these results do not necessarily mean that accessibility should be completely neglected. The opportunity exists to make a positive contribution by improving accessibility, which exerted an indirect influence on both place attachment and place satisfaction. Since 1949, the population has exceeded the original accommodation capacity of the Tanhualin district, so people have begun to build extensions by blocking capillary spaces, thereby decreasing accessibility in this area. In recent years, with the improved economy and living standards, the number of private vehicles rapidly increased. Meanwhile, the logistics of the markets and shops in and around the Tanhualin district continue to produce considerable traffic load. The residents and shop owners must drive into the pedestrian area and park along the street, seriously compromising the safety and comfort of pedestrians in this area. Therefore, optimizing accessibility around historical areas could alleviate the internal traffic pressure and enhance place satisfaction. The potential value could be justified by the evidence that two subway stations have long been planned for construction in this area. However, establishing too much heavy infrastructure might be dangerous if the anticipated gain is very limited, because the total effect of increasing accessibility is much lower for other described factors. Moreover, negative impacts should be anticipated as more people might intensify the pressure on historical areas where infrastructure tends to be insufficient. Meanwhile, the difference should be carefully identified between increasing accessibility and attracting commercial opportunities because a commercially driven strategy may not be the only appropriate way to sustain historical areas. Overwhelming influence from the business sphere might be harmful to the unique characteristics of historical places, weakening the formation of local community. Examples from Fenghuang in Hunan Province, Yangshuo in Guangxi Province, and Dali and Lijiang in Yunnan Province have demonstrated negative results with too much competing commercialization (Bao and Yang 2012).

\section{Optimizing the urban function and place management}

The results showed that urban function has a completely indirect effect on place satisfaction, while management is of no significant influence on place attachment, but exerts a direct influence on place satisfaction. This finding suggested that place attachment could be a somewhat more introversive and spiritually driven factor, while place satisfaction could be more connected to hedonic attributes of external experience. According to the survey, respondents gave relatively low ratings to urban function ( $\mu \mathrm{uf}=4.68$ ) and management ( $\mu \mathrm{ma}=4.67$ ), which compromised the overall quality of this area. Because of its adjacency to the Hubei Academy of Fine Arts, the Tanhualin area has gradually cultivated a renowned cultural context with rich history and culture accumulation where many artists have assembled for creative work, exhibition, and trading. 
However, its identity is not well supported by existing functions within this area. According to our investigation, among the 88 stores open along the main street (street peddlers and cart sales were excluded), $58 \%$ of them were eateries, accounting for almost two-thirds of all the business types. Although some of them were also operated as boutique shops and bars, perhaps in line with the needs of young customers, intensive competition among these homogenized business types was still problematic. Creative establishments, small sales, and entertainment account for $18 \%, 16 \%$, and $2 \%$, respectively. More cultural and historical enhancement is needed to improve the functional diversity in this area. Therefore, the careful positioning of a long-term target is required before initiating any functional plan for historical places. Although alternative ways are needed to promote the land value in a historical place, a strong vision should be established that ensures the protection of valuable cultural resources, which are the basis for the successful operation of all functions. Perhaps it is time to support and cultivate local creative industries that are closely related to the needs of a new era yet framed by the rich connotations of historical places. It is important to realize an organic renewal model that fully respects the local materials, heritage, culture, history, and characteristics of historical places.

\section{Conclusion and recommendations for future research}

Investigations about how people perceive historical places and what makes these places satisfactory continue to be important for urban designers, architects, environmental psychologists, and sociologists. Building a space endowed with a sense of place should be based on parallels between place-making strategies and helpful urban design strategies. For this purpose, a structural equation modelling technique was employed with attitudinal variables to investigate the pathways by which PUDQs influenced placeness factors, and the structural model was validated with an explanatory power. The results presented how these factors synthesized a composite impact on historical places with highly accepted validity of the proposed model. In this model, place attachment was verified as a critical component that links PUDQs to place satisfaction. Among the five proposed PUDQs, walkability and space quality were presented as two most influential factors associated with place attachment and place satisfaction, implying a need to couple these two PUDQs for a successful place-making implementation. To improve the environment pleasurability in historic districts, more attention should also be paid to details such as providing relaxing, comfortable places, improving sanitary conditions, adding hand rails and ramps, and fostering pleasant plantings. To optimize urban function and place management, types of different amenities should be pre-planned to have an equal mix of eateries and creative cultural industries to maintain the sense of place.

Nevertheless, further work is still needed to diminish some possible limitations in this study. First, we only considered local residents in this current study, as the purpose was to validate a local model which is necessary for potential extension rather than to examine a more generalized model, which is to be tested when other stakeholders are taken into account in our future research as the next step.

Second, as our study was conducted based on a Chinese case and relevant cultural background, where participants are mostly local or domestic, there is a need to test more cases to further validate the proposed model in different contexts. Comparisons from cases in other countries could be examined to test the cross-cultural connotations in a broader background. Third, bias might exist for the model estimates because of the ignorance of respondents' personality traits if they are possibly associated with dependent variables. Finally, understanding geographical, financial, and other constraints by asking additional questions may contribute to more generalized discovery in the future study. Moreover, other possible urban design qualities could be involved as independent 
variables to enhance the proposed model for a more comprehensive and powerful explanation. Acknowledgements

This work was supported by the National Natral Science Foundation of China (51408442), Hubei Provincial Natural Science Foundation of China (2018CFB570), and Luojia Young Scholar Project of Wuhan University (SZDW-2018).

\section{References}

Abou-Shouk, Mohamed A., Nagoua Zoair, Mohamed N. El-Barbary, and Mahmoud M. Hewedi. 2017. Sense of place relationship with tourist satisfaction and intentional revisit: Evidence from Egypt. International Journal of Tourism Research 20 (2): 172-181.

Addison, Carey, Sumei Zhang, and Bradley Coomes. 2013. Smart growth and housing affordability: A review of regulatory mechanisms and planning practices. Journal of Planning Literature 28 (3): 215257.

Bao, Ji G., and Yun Yang. 2012. On the local residents' changes of place attachment against the background of tourism commercialization: Cases from Yangshuo west street. Journal of Guangxi University for Nationalities 34 (4): 49-54.

Besussi, Elena, Nancy Chin, Michael Batty, and Paul Longley. 2010. The structure and form of urban settlements. In Remote sensing of urban and suburban areas, ed. Tarek Rashed and Carsten Jürgens, 13-31. New York: Springer.

Buckman, Stephen. 2016. Canal oriented development as waterfront place-making: An analysis of the built form. Journal of Urban Design 21 (6): 785-801. Bryant, Fred B., and Albert Satorra. 2012. Principles and practice of scaled difference chi-square testing. Structural Equation Modelling $A$ Multidisciplinary Journal 19 (3): 372-398.

Byrne, Barbara M. 2001. Structural equation modelling with AMOS: Basic concepts, applications and programming. Mahwah NJ: Lawrence Erlbaum Associates Inc.

Campón-Cerro, Ana, Helena Alves, and Jose Hernández-Mogollón. 2015. Attachment as a factor in generating satisfaction with, and loyalty to, rural tourism destinations. Tourism \& Management Studies 11 (1): 70-76.

Cilliers, Elizelle J., and Wim Timmermans. 2014. The importance of creative participatory planning in the public place-making process. Environment and Planning B: Planning and Design 41 (3): 413-429.

Curtis, Curtis, and Reena Tiwari. 2008. Transitioning urban arterial roads to activity corridors. Urban Design International 13 (2): 105-120.

Carmona, Matthew, Steve Tiesdell, Tim Heath, and Taner Oc. 2003. Public spaces-urban spaces: The dimensions of urban design. Boston: Architectural Press.

Chapman, David W., and Peter J. Larkham. 1999. Urban design, urban quality and the quality of life: Reviewing the department of the environment's urban design campaign. Journal of Urban Design 4 (2): 211-232.

Cervero, Robert, and Kara Kockelman. 1997. Travel demand and the 3Ds: Density, diversity, and design. Transportation Research Part D Transport \& Environment 2 (3): 199-219. 
Chapin, F. Stuart III., and Knapp, Corrine N. 2015. Sense of place: A process for identifying and negotiating potentially contested visions of sustainability. Environmental Science \& Policy 53: 38-46.

Credit, Kevin, and Elizabeth Mack. 2017. Place-making and performance: The impact of walkable built environments on business performance in Phoenix and Boston. Environment and Planning B: Urban Analytics and City Science 46 (2): 264-285. https:// doi.org/10.1177/2399808317710466.

Dupre, K. 2019. Trends and gaps in place-making in the context of urban development and tourism 25 years of literature review. Journal of Place Management and Development 12 (1): 102-120.

Ewing, Reid, and Susan Handy. 2009. Measuring the unmeasurable: Urban design qualities related to walkability. Journal of Urban Design 14 (1): 65-84.

Fan, Jun, and Hong L. Qiu. 2014. Examining the effects of tourist resort image on place attachment: A case of Zhejiang. China. Public Personnel Management 43 (3): 340-354.

Featherstone, Mike. 2007. Consumer culture and postmodernism (published in association with Theory, Culture \& Society). London: Sage.

Florida, Richard L. 2002. The rise of the creative class: And how it's transforming work, leisure, community, and everyday life. New York: Basic Books.

Fornell, Claes, and David F. Larcker. 1981. Evaluating structural equation models with unobservable variables and measurement error. Journal of Marketing Research 18 (1): 39-50.

Friedmann, John. 2007. Reflections on place and place-making in the cities of China. International Journal of Urban and Regional Research 31 (2): 257-279.

Gehl, Jan. 2011. Cities for people. Landscape Architecture Magazine 101 (3): 136-136.

Gospodini, Aspa. 2004. Urban morphology and place identity in European cities: Built heritage and innovative design. Journal of Urban Design 9 (2): 225-248.

Habibah, A., I. Mushrifah, J. Hamzah, A.C. Er, A. Buang, M.E. Toriman, S. Selvadurai, and R. Zaimah. 2013. Place-making of ecotourism in Tasik Chini: From exploratory to the contemporary biosphere reserve. Asian Social Science 9 (6): 84-95.

Hair, Joseph F., William C. Black, Barry J. Babin, and Rolph E. Anderson. 2010. Multivariate data analysis: A global perspective, 7th ed. Upper Saddle River: Pearson Education International.

Hassen, Nadha, and Pamela Kaufman. 2016. Examining the role of urban street design in enhancing community engagement: A literature review. Health \& Place 41: 119-132.

Heidegger, Martin. 1975. Building dwelling thinking. In Poetry, language, thought. Trans. A. Hofstadter, 141-60. New York: Harper and Row.

Hidalgo, M. Carmen, and Bernardo Hernández. 2001. Place attachment: Conceptual and empirical questions. Journal of Environmental Psychology 21 (3): 273-281.

Horner, Mark W. 2004. Exploring metropolitan accessibility and urban structure. Urban Geography 25 (3): 264-284.

Johansson, Maria, Catharina Sternudd, and Mattias Kärrholm. 2016. Perceived urban design qualities and affective experiences of walking. Journal of Urban Design 21 (2): 256-275. 
Jorgensen, Bradley S., and Richard C. Stedman. 2006. A comparative analysis of predictors of sense of place dimensions: Attachment to, dependence on, and identification with lakeshore properties. Journal of Environmental Management 79: 316-327.

Jivén, Gunila, and Peter J. Larkham. 2003. Sense of place, authenticity and character: A commentary. Journal of Urban Design 8 (1): 67-81.

Kalali, Parisa. 2015. Meaningful perception of place: the most effective dimensions and factors. Urban Design International 20 (3): 222-240.

Kelly, Janet, Matt Ruther, Sarah Ehresman, and Bridget Nickerson. 2016. Placemaking as an economic development strategy for small and midsized cities. Urban Affairs Review 53 (3): 435-462.

Krizek, Kevin J. 2003. Neighborhood services, trip purpose, and tour-based travel. Transportation 30 (4): 387-410.

Kyle, Gerard, Alan Graefe, Robert Manning, and James Bacon. 2004. Effects of place attachment on users' perceptions of social and environmental conditions in a natural setting. Journal of Environmental Psychology 24 (2): 213-225.

Kwan, Mei P. 1998. Space-time and integral measures of individual accessibility: A comparative analysis using a point-based framework. Geographical Analysis 30 (3): 191-216.

Kwenye, Jane, and Wayne Freimund. 2016. Domestic tourists' loyalty to a local natural tourist setting: Examining predictors from relational and transactional perspectives using a Zambian context. Tourism Management Perspectives 20: 161-173.

Lalli, Marco. 1992. Urban-related identity: Theory, measurement, and empirical findings. Journal of Environmental Psychology 12 (4): 285-303.

Lee, Tsung H., and Yen L. Shen. 2013. The influence of leisure involvement and place attachment on destination loyalty: Evidence from recreationists walking their dogs in urban parks. Journal of Environmental Psychology 33 (1): 76-85.

Lefebvre, Henry. 1991. The Production of Space. Oxford: Blackwell.

Lew, Alan A. 2017. Tourism planning and place making: Place-making or placemaking? Tourism Geographies 19 (3): 448-466.

Lindelöw, David, Ase Svensson, Catharina Sternudd, and Maria Johansson. 2014. What limits the pedestrian? Exploring perceptions of walking in the built environment and in the context of everyday life. Journal of Transport \& Health 1 (4): 223-231.

Lombard, Melanie. 2014. Constructing ordinary places: Place-making in urban informal settlements in Mexico. Progress in Planning 94: 1-53.

Lu, Yi, Chinmoy Sarkar, and Yang Xiao. 2018. The effect of street-level greenery on walking behavior: Evidence from Hong Kong. Social Science \& Medicine 208: 41-49.

Luque-Martínez, Teodoro, and Francisco Muñoz-Leiva. 2005. City benchmarking: A methodological proposal referring specifically to Granada. Cities 22 (6): 411-423.

Manzo, Lynne C., and Douglas D. Perkins. 2006. Finding common ground: The importance of place attachment to community participation and planning. Journal of Planning Literature 20 (4): 335-350. 
Marshall, Stephen. 2004. Streets and patterns: The structure of urban geometry. London: Routledge. Martin, Deborah. 2003. "Place-framing" as place-making: constituting a neighborhood for organizing and activism. Annals of the Association of American Geographers 93 (3): 730-750.

McCunn, Lindsay J., and Robert Giford. 2018. Spatial navigation and place imageability in sense of place. Cities 74: 208-218.

Miller, Harvey. 1991. Modelling accessibility using space-time prism concepts within geographical information systems. International Journal of Geographical Information Systems 5 (3): 287-301.

Miller, K. F. 2007. Designs on the Public: The Private Lives of New York's Public Spaces. University of Minnesota Press.

Morgan, Paul. 2010. Towards a developmental theory of place attachment. Journal of Environmental Psychology 30 (1): 11-22.

Morley, I.B. 2009. The contemporary Chinese metropolis: modernity, globalisation, and conceptual meanings. Design Principles and Practices: An International Journal 3 (1): 309-322.

Motloch, John. 1990. Placemaking: Urban landscape system management. Systems Research 7 (4): 273-285.

Norberg-Schulz, Christian. 1980. Genius loci: towards a phenomenology of architecture. New York: Rizzoli.

Othman, Sumaiyan, Yukio Nishimura, and Aya Kubota. 2013. Memory association in place making: A review. Procedia-Social and Behavioral Sciences 85: 554-563.

Pancholi, S., T. Yigitcanlar, and M. Guaralda. 2015. Public space design of knowledge and innovation spaces: learnings from Kelvin Grove Urban Village, Brisbane. Journal of Open Innovation Technology Market and Complexity 1 (1): 1-17.

Phillips, David R., Kevin H.C. Cheng, Anthony G.O. Yeh, and Oi-Ling Sui. 2010. Person-environment $(\mathrm{P}-\mathrm{E}) \mathrm{ft}$ models and psychological well-being among older persons in Hong Kong. Environment and Behavior 42 (2): 221-242.

Pivo, Gary, and Jeffrey D. Fisher. 2011. The walkability premium in commercial real estate investments. Real Estate Economics 39 (2): 185-219.

Prayag, Girish, and Chris Ryan. 2012. Antecedents of tourists' loyalty to Mauritius: The role and influence of destination image, place attachment, personal involvement, and satisfaction. Journal of Travel Research 5 (3): 342-356.

Proshansky, Harold M. 1978. The city and self-identity. Environment \& Behaviour 10 (2): 147-169.

Ram, Y., P. Björk, and A. Weidenfeld. 2016. Authenticity and place attachment of major visitor attractions. Tourism Management 52: 110-122.

Ramkissoon, Haywantee, and Felix T. Mavondo. 2015. The satisfaction-place attachment relationship: Potential mediators and moderators. Journal of Business Research 68 (12): 2593-2602.

Ramkissoon, Haywantee, Liam David G. Smith, and Betty Weiler. 2013. Testing the dimensionality of place attachment and its relationships with place satisfaction and pro-environmental behaviours: A structural equation modelling approach. Tourism Management 36 (36): 552-566. 
Ramkissoon, Haywantee, Betty Weiler, and Liam David G. Smith. 2012. Place attachment and proenvironmental behaviour in national parks: The development of a conceptual framework. Journal of Sustainable Tourism 20 (2): 257-276.

Relph, Edward C. 1976. Place and placelessness. Geographical Review 68 (1): 116.

Scannell, Leila, and Robert Giford. 2010. Defning place attachment: A tripartite organizing framework. Journal of Environmental Psychology 30: 1-10. S

chneekloth, Lynda H., and Robert G. Shibley. 1995. Placemaking: The art and practice of building communities. New York: Wiley.

Sepe, Marichela, and Michael Pitt. 2013. Improving liveability and attractiveness by preserving place identity in emblematic thoroughfares: A method and a case study. Urban Design International 18 (3): 229-249.

Sepe, Marichela, and Michael Pitt. 2014. The characters of place in urban design. Urban Design International 19 (3): 215-227. S

him, Changsup, and Carla A. Santos. 2014. Tourism, place and placelessness in the phenomenological experience of shopping malls in Seoul. Tourism Management 45: 106-114.

Sirgy, Joseph M. 2010. Toward a quality-of-life theory of leisure travel satisfaction. Journal of Travel Research 49 (2): 246-260.

Stedman, R C. 2002. Toward a social psychology of place: Predicting behavior from place-based cognitions, attitude, and identity. Environment \& Behavior 34 (5): 561-581.

Stedman, Richard C. 2003. Is it really just a social construction: The contributions of the physical environment to sense of place. Society and Natural Resources 16: 671-685.

Tan, Siow-Kian, Siow Hooi Tan, Yon-Sin Kok, and Shay-Wei Choon. 2018. Sense of place and sustainability of intangible cultural heritage-the case of George town and Melaka. Tourism Management 67: 376-387.

Trancik, Roger. 1986. Finding lost space: Theories of urban design. New York: Wiley.

Trentelman, Carla Koons. 2009. Place Attachment and community attachment: A primer grounded in the lived experience of a community sociologist. Society \& Natural Resources 22 (3): 191-210.

Tsai, Shu-Pei. 2012. Place attachment and tourism marketing: Investigating international tourists in Singapore. International Journal of Tourism Research 14 (2): 139-152.

Voorde, Tim V.D., Wolfgang J. Jacquet, and Frank Canters. 2011. Mapping form and function in urban areas: An approach based on urban metrics and continuous impervious surface data. Landscape \& Urban Planning 102 (3): 143-155.

Wu, Fulong. 2003. The (post-) socialist entrepreneurial city as a state project: Shanghai's reglobalisation in question. Urban Studies 40 (9): 1673-1698.

Wynveen, Christopher J., Gerard T. Kyle, and Stephen G. Sutton. 2012. Natural area visitors' place meaning and place attachment ascribed to a marine setting. Journal of Environmental Psychology 32 (4): 287-296. 
Williams, Stephen, and Alan A. Lew. 2015. Tourism geography: Critical understanding of place, space and experience, 3rd ed. London: Routledge.

Williams, Daniel R., and Jerry J. Vaske. 2003. The measurement of place attachment: Validity and generalizability of a psychometric approach. Forest Science 49: 831-840.

Yuksel, Atila, Fisun Yuksel, and Yasin Bilim. 2010. Destination attachment: Effects on customer satisfaction and cognitive, affective and conative loyalty. Tourism Management 31 (2): 274-284.

Zakariya, Khalilah, Nor Z. Harun, and Mansor Mazlina. 2015. Place meaning of the historic square as tourism attraction and community leisure space. Procedia-Social and Behavioral Sciences 202: 477486.

Zenker, Sebastian, Sibylle Petersen, and Andeas Aholt. 2013. The Citizen Satisfaction Index (CSI): Evidence for a four basic factor model in a German sample. Cities 31 (31): 156-164. Z

enker, Sebastian, and Natascha Rütter. 2014. Is satisfaction the key? The role of citizen satisfaction, place attachment and place brand attitude on positive citizenship behavior. Cities 38 (4): 11-17.

Zhang, Ming, and Wenjia Zhang. 2018. When context meets self-selection: The built environmenttravel connection revisited. Journal of Planning Education and Research.

https://doi.org/10.1177/07394 56X18755495 